\title{
Obsolescencia de la protección a los inversores extranjeros después de la crisis argentina
}

\author{
Michael Mortimore y Leonardo Stanley
}

A

diferencia de lo ocurrido ante crisis anteriores, cuando las discusiones entre las partes (acreedores y deudores, inversores y países receptores) se encuadraban en algún tipo de marco institucional, la crisis experimentada por Argentina a partir del 2001 mostró a un país abandonado a su suerte, no en una sino en dos oportunidades. Pero aunque inicialmente los inversores extranjeros habían logrado modificar las reglas en su provecho, obteniendo mayor protección y más seguridad jurídica, la situación terminó siéndoles desfavorable. La experiencia

Michael Mortimore

Jefe, Unidad de Inversiones y Estrategias Empresariales,

División de Desarrollo Productivo y Empresarial,

CEPAL

- michael.mortimore@cepal.org

Leonardo Stanley

Centro de Estudios de Estado y Sociedad (CEDES),

Buenos Aires

- Istanley@cedes.org de Argentina sugiere que, dado el peso declinante de las instituciones financieras internacionales, en la situación actual las soluciones asimétricas no son duraderas y que los gobiernos democráticos terminarán por dar mayor prioridad a sus electores que a los inversionistas extranjeros cuando estén obligados a elegir entre unos y otros. Esto lleva a preguntarse si el caso argentino es una excepción o bien marca un debilitamiento de la protección a la inversión extranjera. 


\section{I}

\section{Introducción}

La inversión extranjera ha desempeñado un papel importante en la economía argentina durante los últimos 30 años, y especialmente en los decenios de 1970 y 1990, cuando los ingresos alcanzaron máximos de hasta $8 \%$ del producto interno bruto (gráfico 1). Estas alzas se asociaron con tres clases de inversionistas: primero, en la década de 1970, con los bancos transnacionales que extendieron cuantiosos préstamos en consorcio; luego, en la década de 1990, con los intermediarios financieros que colocaron voluminosas sumas en bonos y con las empresas transnacionales que efectuaron fuertes inversiones directas.

Pese a lo dicho, el 23 de diciembre del 2001 Argentina estremeció a la comunidad financiera internacional, al declarar la cesación de pagos sobre su deuda pública por un monto superior a los 100.000 millones de dólares, que involucraban más de 150 bonos bajo la legislación de ocho jurisdicciones diferentes. La magnitud del caso resulta evidente si se considera que, al momento de ese incumplimiento, la deuda argentina representaba la cuarta parte del total de deuda transado en el mercado de bonos emergentes. Simultáneamente, en enero de 2002, hubo una fuerte devaluación del peso argentino y el gobierno "pesificó" las tarifas de las empresas de servicios públicos, lo cual significó no respetar contratos firmados con empresas transnacionales que operaban en el país y, en el contexto de los tratados bilaterales de inversión, generó demandas internacionales contra Argentina. El caso argentino ha sido un hito en la historia financiera moderna no solo por su magnitud, sino también porque combinó dos crisis distintas y por las circunstancias institucionales en que tales crisis tuvieron lugar. La crisis de la deuda revistió extremos tales que la balanza se inclinó a favor del deudor. La crisis de las inversiones extranjeras directas (IED), en cambio, tuvo repercusiones de largo plazo, vinculadas al comportamiento de la inversión en los sectores pertinentes.

Los autores agradecen los comentarios de un juez anónimo. Las opiniones expresadas en este artículo son de exclusiva responsabilidad de los autores y pueden no coincidir con las de las organizaciones a las cuales pertenecen.
Para empezar, el conflicto entre acreedores y deudores soberanos presentó ribetes novedosos. A diferencia de lo observado durante la década de 1980, la crisis financiera argentina mostró al país con mayor poder de negociación, al enfrentar una masa de acreedores dispersa y poco organizada, compuesta por miles de tenedores de bonos, en lugar de un grupo de bancos transnacionales estratégicamente agrupados al momento del colapso. Así, Argentina no se vio obligada a renegociar bajo coacción. A esto se sumó la errada estrategia de los "bonistas", quienes, en su afán por limitar el poder del deudor, bloquearon cualquier intento de renegociación, postura que, en este caso al menos, les terminó jugando en contra (al menos en el caso argentino). También resultó evidente la ausencia de un marco institucional, puesto que el Fondo Monetario Internacional (FMI) se vio imposibilitado de desempeñar un papel más significativo al momento de la renegociación. Por último, no debe pasarse por alto la división imperante dentro del Grupo de los Siete (G7). Estos dos últimos factores obligaron a Argentina a buscar una solución propia.

En lo que respecta al sector real, es decir, a la IED en servicios de utilidad pública, si bien el esquema bilateral para el tratamiento de las inversiones existía desde finales de la década de 1950, su utilización se vino a generalizar solamente en la de 1990. En esta última década no solo hubo un importante aumento de las corrientes de IED hacia los países en desarrollo, sino que también se observó el despertar del sistema de justicia arbitral. Argentina pronto se convirtió en uno de los más fervientes partidarios del esquema bilateral, postura que llevó al país a firmar más de 50 tratados bilaterales sobre inversiones y adherir al Centro Internacional de Arreglo de Diferencias relativas a Inversiones (CIADI), del Banco Mundial.

Las garantías otorgadas en los contratos con los inversores extranjeros directos llevaron a estos, sobre todo a aquellos que tenían participación en empresas prestadoras de servicios de utilidad pública, a demandar al país una vez declarada la Ley de emergencia económica. El proceso que allí se inició ha hecho que Argentina tenga que enfrentar más de 40 pleitos, aglutinando por sí sola cerca del $40 \%$ de los casos pendientes ante el CIADI, la principal institución internacional 
GRÁFICO 1

Argentina: Ciclos de inversión extranjera, 1975-2004

(En porcentajes del PIB)

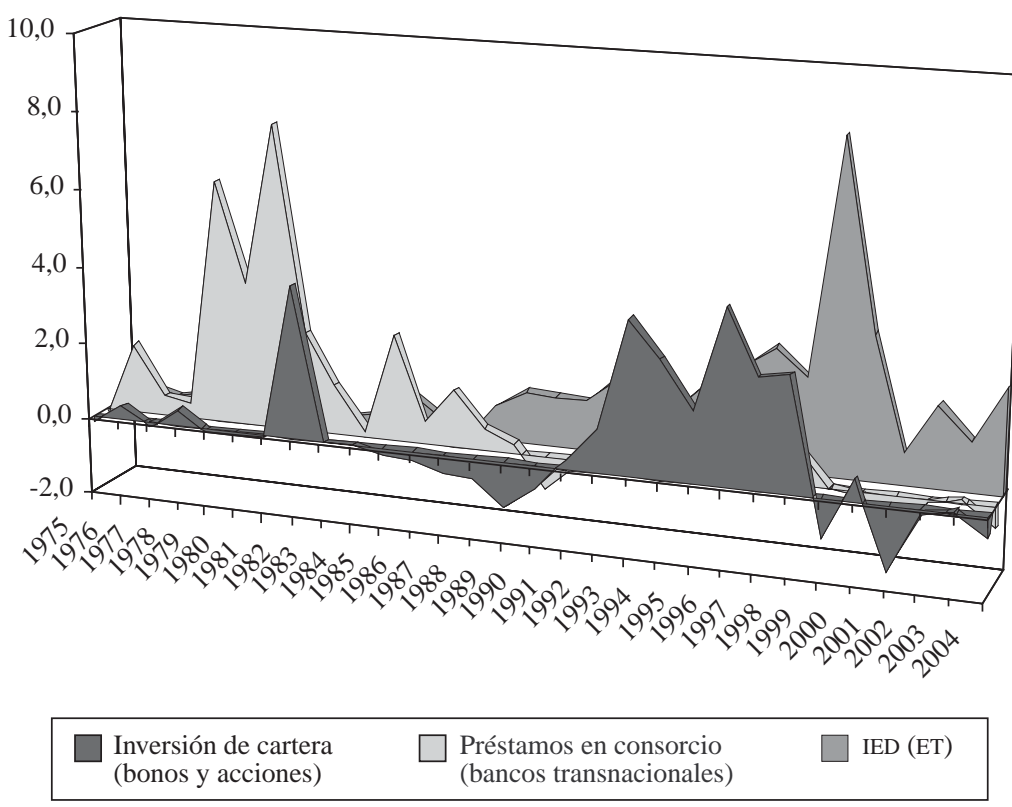

Fuente: Elaboración propia sobre la base de información de Banco Mundial (2004).

dedicada al arreglo de diferencias entre inversionistas extranjeros y gobiernos.

Diversos autores han investigado la causa de la crisis reciente, pero no existe consenso respecto al factor que le dio origen. Algunos culpan a las autoridades argentinas por adoptar políticas que terminaron por llevar el país a la crisis. Otros sugieren que los acreedores e inversionistas fueron poco cautelosos en el momento de decidir el destino de su capital. En el presente trabajo se intentará poner de relieve otro aspecto: el papel de las instituciones financieras internacionales (IFI).

Pese al fuerte crecimiento de las corrientes de capital e inversión extranjera directa (IED) en la déca- da de 1990 las instituciones financieras internacionales siguieron siendo débiles, irrelevantes o poco consecuentes. Siendo este el caso, frente a la crisis prevaleció la opción de mercado (sistema financiero) o la del esquema bilateral en materia de inversiones, aunque ninguna de las dos ofrecía soluciones duraderas.

En lo que sigue se pretende abordar estos dos aspectos, indagando en la evolución de las reglas financieras y las asociadas al tratamiento de la IED. Se analizan los problemas de Argentina en función de cada uno de los conflictos que el país atravesó al momento de romper con la convertibilidad y, por último, se formulan algunas reflexiones en torno a su impacto sobre la protección a los inversionistas extranjeros. 


\section{II}

\section{La crisis financiera}

\section{Sistema financiero internacional: ausente}

El esquema financiero que surgió tras la Conferencia de Bretton Woods (1944) comenzó a resquebrajarse en la década de 1970. Rebosantes de liquidez por la disponibilidad de depósitos (eurodólares) y por el alza significativa del precio del petróleo (petrodólares), los bancos transnacionales se lanzaron en busca de nuevos clientes, principalmente entre los países recientemente descolonizados y los latinoamericanos. En América Latina, la amplia disponibilidad de fondos disparó un nuevo modelo de crecimiento. Pero a pesar de las precauciones de los inversores ${ }^{1} \mathrm{y}$ los beneficios que el nuevo modelo traía para los deudores, el terreno estaba abonado para que se desencadenara una fuerte crisis, la que se desencadenó en 1982.

Tras la declaración formal de incumplimiento de Argentina se generó un amplio debate respecto a la forma en que debía enmarcarse la renegociación, dividiéndose las aguas entre quienes creían conveniente introducir un esquema institucional y quienes planteaban que la crisis debía ser resuelta por el mercado (Eichengreen, 1988). La crisis evolucionó en tres etapas. En la primera, los bancos transnacionales intentaron cargar todos los costos a los países deudores a través de préstamos de reestructuración, que significaban comisiones e intereses altísimos y las severas condiciones económicas del FMI. En la segunda, las instituciones financieras internacionales definieron un programa de reestructuración destinado a ayudar a los países deudores a enfrentar la carga de su deuda, e introdujeron exigencias a los bancos transnacionales para que prestaran más. Frente a la negativa de estos bancos, en la tercera etapa hubo un respaldo más activo del Departamento del Tesoro de los Estados Unidos a través de mecanismos para reducir el valor de la deuda (bonos Brady, canje de deuda por capital, etc.). De esta manera, ajena al debate, el proceso de reestructuración de la deuda adquirió una naturaleza esencialmente

\footnotetext{
${ }^{1}$ Entre otras cláusulas, destacaba la imposición, en los contratos de préstamos originados en el Reino Unido y los Estados Unidos, de una que obligaba a los deudores a renunciar a su soberanía ("waive") en caso de disputa. Según los acreedores, esta estrategia haría imposible la cesación de pagos.
}

privada y un carácter asimétrico que llevó a los deudores a soportar el mayor peso del ajuste. Dicho proceso perduró hasta que se hizo evidente que la crisis no tendría solución sin reducir la deuda y cargar parte del ajuste a los acreedores principales. Lamentablemente, llegar a esta decisión demoró aproximadamente 10 años (Mortimore, 1989; CET, 1990; CEPAL, 1989).

Al inicio de 1990 la situación había cambiado nuevamente. El fin de la crisis marcó no solo el regreso de capitales a los países de la región, sino también una modificación en términos de financiamiento (reemplazo de los créditos por bonos). Sin embargo, con la irrupción en 1994 de la "crisis del tequila" (originada en México) se reabrió el debate acerca de cómo instrumentar un marco institucional para tratar con este tipo de situaciones. En ese momento surgió un amplio espectro de opciones, entre las cuales algunas privilegiaban la introducción de cláusulas de acción colectiva y otras la institucionalización de algún esquema de reorganización económico-financiera, principalmente por las líneas del régimen de quiebras vigente en los Estados Unidos.

Entre quienes favorecían la postura institucional se encontraba Jeffrey Sachs, ${ }^{2}$ quien proponía un régimen de quiebras de alcance internacional basado en el capítulo 11 de la Ley de quiebras estadounidense. La idea era establecer un marco jurídico que diera a los gobiernos de los países en crisis un respaldo temporal para renegociar con sus acreedores antes de la iniciación de las demandas legales correspondientes.

Desde la visión de mercado se abogaba por que el conflicto se resolviera entre quienes habían pactado el contrato (el deudor soberano y los acreedores), sin la injerencia de terceros (por ejemplo, un árbitro que podría ser el FMI u otro organismo internacional). Pero, reconociendo la imposibilidad de alcanzar un acuerdo que satisficiera a la totalidad de los "bonistas", numerosos académicos y encargados de la formulación de políticas $^{3}$ comenzaron a considerar la conveniencia de

\footnotetext{
2 Véase Sachs (1995).

${ }^{3}$ La propuesta sería apoyada, entre otros, por Eichengreen, Portes y otros (1995), mientras que a nivel gubernamental sería respaldada por un informe del Grupo de los Diez (G-10, 1996).
} 
introducir algún tipo de cláusula que permitiera que el grupo mayoritario de "bonistas" renegociara con el deudor soberano. ${ }^{4}$ Con la introducción de una cláusula de acción colectiva se resolvió este problema, reduciendo el poder de los acreedores que rehusaran participar en la renegociación (holdouts).

Sin embargo, a los acreedores más duros esta alternativa no les parecía viable, pues estimaban que cualquier tipo de cláusula que rompiera con la condición de unanimidad debía considerarse una erosión de sus derechos.

El debate estaba en este punto cuando dos hechos vinieron a perturbarlo en el 2001. Por un lado, en los Estados Unidos asumió el gobierno el Presidente George W. Bush, lo que tendría mucha importancia en el debate posterior. ${ }^{5}$ Por otro lado, la situación en Argentina continuó agravándose, apuntando a que la cesación de pagos sería inevitable.

Esta serie de acontecimientos llevó a que la nueva Economista Jefe del FMI, Anne Krueger, propusiera el mecanismo de reestructuración de deuda soberana (SDRM). Dicho mecanismo se basaba en la Ley de quiebras estadounidense, pero incluía elementos de dos capítulos de esa ley: del capítulo 11 (Corporaciones) y del capítulo 9 (Municipalidades). Los aspectos más destacados de esta propuesta tenían que ver con la mayor injerencia del FMI en el proceso de administración de la quiebra, y con el establecimiento de una nueva institución -el Sovereign Debt Dispute Resolution Forum (SDDRF) - para evaluar el proceso de quiebra soberana.

Este esquema generó el lógico rechazo de la comunidad financiera, por considerar que las crisis debían de ser resueltas por el mercado y que había que minimizar la capacidad negociadora de los deudores. Tal fue la postura sustentada por el Instituto de Finanzas Internacionales (IFI, 1999 y 2001), entidad que consideró ilegítimos los intentos por dilatar el pago de la deuda, aunque fuese en forma momentánea, y la opción que implicara caer en mora.

Al mismo tiempo, el Secretario del Tesoro estadounidense reclamaba una mayor injerencia del mercado, y, aunque parezca paradójico, sugería que en algún momento los inversores deberían asumir su par-

\footnotetext{
${ }^{4}$ Tal como sucede en el caso de bonos emitidos bajo la jurisdicción de Londres.

${ }^{5}$ El recambio presidencial implicaba también el reemplazo de la dupla Larry Summers (Departamento del Tesoro de los Estados Unidos) y Stanley Fischer (FMI) por R. Taylor y Anne Krueger, respectivamente.
}

te en la solución del conflicto. ${ }^{6}$ Esta nueva postura involucraba el concurso de cinco principios nuevos que deberían orientar la solución de la crisis (Machinea, 2002, pp. 31-32): i) que esa resolución no implicara una reducción de las obligaciones de los países deudores; ii) que los acreedores no creyeran que la asistencia oficial los protegería a ellos ante situaciones de riesgo moral; iii) que la participación del sector privado pudiese ayudar a reducir las necesidades financieras del sector oficial; iv) que, en la medida de lo posible, la participación del sector privado tomase la forma de esquemas voluntarios acordados entre deudores y acreedores, y v) que ninguna categoría de deuda privada recibiese un tratamiento privilegiado. Estas directrices se aplicarían caso a caso, mientras que el FMI tendría que afinar los detalles.

De esta forma, el debate terminaba más proclive a una solución de mercado, arrastrando a la entidad internacional pertinente, el FMI, a un menor protagonismo. El primer país que tendría que afrontar este nuevo enfoque iba a ser Argentina. Sin embargo, debido a la indefinición acerca del esquema de renegociación y a la falta de protagonismo del FMI, Argentina terminaría buscando una solución propia al momento de lanzar el canje de la deuda.

\section{Convertibilidad en Argentina: origen y crisis}

Con el lanzamiento del plan de convertibilidad en marzo de 1991 en virtud de la Ley de convertibilidad, el gobierno de Menem logró estabilizar la economía después del caos que significó el período de la crisis de la deuda en el decenio de 1980. Se introdujo un tipo de cambio fijo (un dólar $=$ un peso), que, aunque costoso en términos de política económica, pronto tuvo una alta aceptación. El "atarse las manos" en materia fiscal y monetaria que implicaba el régimen de conversión dio credibilidad ante los acreedores externos y las instituciones multilaterales.

En forma más o menos simultánea, se avanzó con un ambicioso plan de privatizaciones y se lanzó un proceso de desregulación y liberalización, comercial y financiera, de la economía. Las privatizaciones pronto se convirtieron en uno de los elementos clave del nuevo programa económico. Desde una perspectiva agregada,

\footnotetext{
${ }^{6} \mathrm{Al}$ adoptar esta postura, se creía estar reduciendo el problema de riesgo moral, evitando así que los recursos de los organismos internacionales fuesen usados para minimizar el riesgo de los inversores privados relativo a sus inversiones en los mercados emergentes.
} 
la venta de activos públicos y el uso del esquema de capitalización de la deuda (CET, 1990, p. 85) permitieron que Argentina atrajera nueva IED, redujera la deuda externa, y también quitara de la órbita pública las obligaciones financieras que generaban las empresas públicas. Desde una visión microeconómica, el proceso pronto sería criticado por centrarse en la búsqueda de credibilidad (Gerchunoff y Canovas, 1995), lo que terminaría atando la suerte de las empresas privatizadas al éxito del plan de convertibilidad.

En cuanto al desempeño macroeconómico, el plan mostró sus efectos en poco tiempo, dejando atrás la época de hiperinflación e inestabilidad: la inflación se redujo en forma asombrosa y la economía, impulsada por la demanda interna, creció sin interrupciones merced al incremento de los salarios reales y la reaparición del crédito, aunque generando un déficit en la balanza comercial. Pero también las inversiones estaban en alza. Así, el país entró en un sendero de crecimiento sólido, que llevó a la economía a una expansión del orden de $9 \%$ anual en 1994, al mismo tiempo que subía la productividad (Stallings and Peres, 2000, p. 78). Simultáneamente, la deuda externa de origen público se reducía en virtud de los bonos Brady.

De esta forma, el país clasificó entre aquellos que habían llevado a cabo las reformas en menos tiempo, lo que le ganó la adhesión y el aplauso tanto de la comunidad financiera internacional como de las instituciones financieras internacionales con sede en Washington (el FMI, el Banco Mundial y el Banco Interamericano de Desarrollo).

La economía siguió su rumbo ascendente hasta que hizo su aparición la crisis del tequila; pero este desafío fue superado pronto, lo que renovó la confianza en el modelo. Sin embargo, la situación comenzó a modificarse hacia la segunda mitad de la década de 1990, con la irrupción de una serie de crisis financieras, la primera de las cuales se originó en Asia oriental. Y, a partir de 1998, la economía argentina inició su ciclo descendente, que terminaría en depresión y crisis. ${ }^{7}$

\section{Incumplimiento declarado y renegociación de la deuda pública}

Treinta y ocho meses después de declarada la cesación de pagos, y sin ayuda alguna del FMI, Argentina

\footnotetext{
${ }^{7}$ Las causas esgrimidas para explicar el fracaso del esquema de convertibilidad han sido variadas, aunque la mayoría de las explicaciones pueden aglutinarse en tres grupos diferenciados: razones estructurales, u originadas en la tendencia a la sobrevaluación del
}

logró salir del incumplimiento, cuando su oferta obtuvo una amplia adhesión (más de $75 \%$ ) entre los "bonistas", alcanzando lo que ningún otro país había logrado antes: no solo el recorte (la "quita") que debieron soportar los tenedores de bonos fue máxima, sino que también se logró que los acreedores aceptaran una extensión del plazo de pago y una reducción de las tasas de interés finalmente reconocidas. Mientras en otras reestructuraciones los acreedores debieron aceptar algunas de las tres medidas mencionadas, en el caso argentino debieron aceptarlas todas (The Economist, 2005).

¿Cuáles son los factores que permiten entender por qué Argentina pudo imponer una solución unilateral en la renegociación de la deuda?

A grandes rasgos, podría decirse que esa solución iba a depender de la propuesta de canje que hiciera el gobierno, del poder de negociación de cada una de las partes y de la postura que adoptaran las instituciones financieras internacionales y los países desarrollados en el proceso de renegociación.

La propuesta del gobierno fue unilateral y ambiciosa. El esquema de "juego" que siguió Argentina puede definirse como uno de no cooperación ("lo tomas o lo dejas"), bajo el supuesto de que el poder de negociación de los acreedores se debilitaría con el paso del tiempo. El costo a corto plazo para el país era mínimo, ya que Argentina no tenía posibilidad alguna de conseguir financiamiento externo en mercados financieros internacionales. Los recursos adicionales con los que contaba el gobierno gracias al no pago de la deuda externa, la introducción de nuevos impuestos (retenciones a las exportaciones), el mayor nivel de actividad económica y probablemente la mejora en la gestión tributaria, le permitieron al nuevo gobernante, el Presidente Kirchner, adoptar una estrategia de negociación más dura con los acreedores.

El carácter unilateral de la oferta se reforzó con un marcado desinterés del gobierno de Argentina por encontrar algún tipo de interlocutor. ${ }^{8}$ En este sentido, todas las acciones del gobierno tuvieron por finalidad impedir la coordinación de los acreedores. Esto

tipo de cambio; razones fiscales, o resultantes de la falta de disciplina fiscal del gobierno; y razones de comportamiento, que explican el origen de la crisis por el surgimiento de expectativas irreales.

${ }^{8}$ Esta estrategia sería reforzada posteriormente por el Ministro de Economía, con la fijación del piso mínimo necesario para considerar al canje como exitoso ( $50 \%$ de adhesión); con la sanción de la denominada Ley cerrojo, que prohibió al gobierno reabrir el canje sin la aprobación del Congreso Nacional, y con la actitud de no permitir la injerencia del FMI en las negociaciones con los acreedores. 
implicaba adoptar una postura de no retorno: de ahí en adelante, la cuestión sería conocer el nivel de adhesión que pudiese lograr el canje. Una adhesión alta garantizaba el éxito de la operación, aunque la apuesta era arriesgada porque un fracaso conllevaba la reunificación del bloque acreedor detrás de la exigencia de una nueva propuesta de canje. Al considerar la probabilidad de éxito de la estrategia, el gobierno contaba con un "piso de adhesión" significativo, dado que alrededor del $30 \%$ del acervo de deuda estaba en manos de agentes financieros locales (la Administradora de Fondos de Jubilaciones y Pensiones, compañías de seguros, fondos institucionales, entidades financieras y otros) cuya adhesión se daba por descontada. En definitiva, la falta de cohesión entre las diversas organizaciones representativas de los acreedores terminó por beneficiar al gobierno.

La oferta unilateral, sin embargo, contó con el apoyo indirecto del resto de los actores. Por un lado, hubo una nula incidencia de las instituciones financieras internacionales al momento de lanzarse el canje, lo que se explica por el disenso existente respecto a cómo lidiar con este tipo de situaciones. ${ }^{9}$ Por otro lado, no se dio una posición monolítica entre los países desa- rrollados, y la postura del gobierno del Presidente Bush fue de laissez faire respecto al tratamiento de las crisis soberanas (Roubini, 2005). De esta forma, tanto la no injerencia del FMI como la falta de cohesión dentro del G7 terminaron favoreciendo al deudor.

Tampoco puede descartarse el aporte de una serie de factores exógenos. La situación económica internacional, asociada a la presencia de tasas de interés bajas en los Estados Unidos, y el descenso en los márgenes de los bonos emergentes, mejoraron las condiciones de la oferta sin costos para el país. ${ }^{10}$ También debe considerarse que el valor de los bonos en el mercado al momento de lanzarse el canje no era tan alejado de lo que estaba proponiendo el gobierno (Roubini, 2005).

El resultado del canje superó con creces las expectativas argentinas. El hecho de que Argentina haya resuelto su situación de cese de pagos en forma unilateral y sin la injerencia de las instituciones financieras internacionales ha enviado fuertes señales a los mercados financieros. Frente a la inoperancia de dichas instituciones y la existencia de (numerosos) acreedores e inversores con ganas de dar una lección a Argentina ${ }^{11}$ ¿puede revertirse la situación o habrá más deudores soberanos que sigan el "ejemplo" argentino?

\section{III}

\section{La otra crisis: la inversión extranjera directa en los servicios de utilidad pública}

\section{Reglas o facultad discrecional en el sistema internacional}

A partir de mediados del siglo XX, la imposibilidad de alcanzar un consenso a nivel multilateral sobre la protección que había de otorgarse a la IED fue fortaleciendo al bilateralismo. A la salida de la segunda guerra mundial se realizó la Conferencia de las Naciones Unidas sobre Comercio y Empleo (1948), de la cual debía surgir una "organización internacional de comercio (ITO)", que se ocuparía de todo lo relativo a comercio e inversión. Sin embargo, en la reunión sólo se llegó

\footnotetext{
${ }^{9}$ A dicha indefinición podría sumarse la escasa credibilidad que tendría el FMI (fundamentalmente ante el gobierno argentino) si intentara mediar entre las partes (FMI, 2004).
}

a un acuerdo en materia comercial, el Acuerdo General sobre Aranceles Aduaneros y Comercio (GATT). El escaso interés en el tema de la inversión solo se modificó al momento de iniciarse la Ronda Uruguay (1982), cuando se comenzó a debatir el proceso de fortalecimiento de la inversión extranjera. Este proceso terminó en una serie de acuerdos multilaterales parciales sobre medidas en materia de inversión relacionada con

\footnotetext{
${ }^{10} \mathrm{Al}$ disminuir la tasa de descuento utilizada en el cálculo del valor presente de la oferta.

${ }^{11}$ El exitoso canje unilateral no debe opacar el hecho de que $\mathrm{Ar}-$ gentina enfrentará serios problemas si intenta volver a los mercados financieros internacionales. Además, la deuda privada externa descontada todavía representa una carga financiera importante que tendría que empezar a pagar en el futuro. A medida que se vea obligada a buscar financiamiento externo se debilitará su actual poder de negociación.
} 
el comercio (TRIM), el comercio de servicios (AGCS), la inclusión de un tratado especial en materia de energía (Energy Chapter $)^{12}$ y aspectos de los derechos de propiedad intelectual relacionados con el comercio (ADPIC). Sin embargo, cualquier intento por introducir algún tipo de acuerdo en materia de inversiones estaría destinado al fracaso, como se vio con ocasión de la iniciativa de un acuerdo multilateral sobre inversiones lanzada por la Organización de Cooperación y Desarrollo Económicos (OCDE) y de tentativas posteriores en el ámbito de la OMC (Declaración de Singapur y Declaración Ministerial en Doha).

De esta forma, el proceso de transformación económica y política iniciado en la década de 1980 y profundizado en la de 1990 desencadenó la firma de numerosos tratados bilaterales de inversión, con lo cual se generalizó la aplicación del esquema bilateral.

El éxito de dicho esquema no puede disociarse del planteamiento de Kydland y Prescott (1977), sobre la conveniencia de establecer reglas en materia de política económica, en lugar de dejarla librada a un manejo discrecional. Si se consideran las características propias del concepto de inversión, el mensaje anterior puede considerarse pertinente. Esto porque, a diferencia de las corrientes de comercio, la llegada de inversiones tiene importantes consecuencias futuras, lo que las torna más expuestas a oportunismos del gobierno. ${ }^{13}$ Este mensaje cobra mayor importancia cuando la IED que entra al país se dirige a los servicios de utilidad pública, actividad en la cual la naturaleza intertemporal del problema se hace más evidente, dada la injerencia del Estado en la regulación de las tarifas, las inversiones y la calidad del servicio. En este caso, el problema de potestad administrativa discrecional u oportunismo del gobierno puede ser más serio, por lo que la falta de compromisos contractuales puede llevar a las empresas a reducir sus inversiones o, en el caso más extremo, a no invertir. Para evitar tal situación, el gobierno estableció normas y garantías, como una manera de disminuir su propia capacidad de modificar los contratos. ${ }^{14}$

En lo que se refiere a los derechos de los inversores, la adopción de reglas se asoció con la firma de

12 Un tratado de carácter multilateral concebido para inducir la participación del sector privado en el sector energético de las ex repúblicas soviéticas.

${ }_{13}$ Tal oportunismo surge por el carácter intertemporal de la relación, pues el gobierno puede verse tentado a modificar las reglas iniciales.

14 Desde otra perspectiva, cuanto más "completo" sea el contrato otorgado, mayor será el compromiso del gobierno de no renegociar contratos. tratados bilaterales sobre inversiones y con la adhesión a instituciones internacionales de arreglo de diferencias entre el inversionista y el Estado (CIADI u otras instancias similares). El fuerte impulso que adquirió el esquema bilateral hizo que los menos de 400 tratados existentes en 1989 llegaran a 2.392 en el 2004, de los cuales el 70\% estaba vigente (UNCTAD, 2005a). En cuanto al CIADI, mientras hace una década este centro tenía solo cinco casos pendientes por un valor de 15 millones de dólares, a fines de 2005 los casos eran 113, por un valor de 30.000 millones de dólares (Dañino, 2005).

Aunque el esquema bilateral que se estaba fortaleciendo lograba armonizar reglas, presentaba ciertas desventajas comparado con el sistema multilateral. Sin duda alguna, sus beneficios terminaban favoreciendo de manera totalmente asimétrica a los inversores, que obtenían importantes garantías. Así, para los países exportadores de capital, facilitaba y protegía la inversión de sus connacionales en el exterior, transformándose en una vía para introducir mayores exigencias (Moltke y Mann, 2004).

En lo que respecta a los países receptores de IED, el esquema se presentaba como conveniente, ya que su introducción era una señal positiva ante los inversores extranjeros. Sin embargo, su eficacia sería posteriormente puesta en duda.

En un estudio econométrico (UNCTAD, 1998) se muestra la inexistencia de algún tipo de relación causal entre las corrientes de IED y la firma de tratados bilaterales sobre inversiones. ${ }^{15} \mathrm{Al}$ considerar los flujos de IED provenientes de los países desarrollados, Hallward-Driemeier (2003) encuentra que el análisis no permite concluir que una mayor protección pueda convertirse en un elemento conductor para atraer inversión adicional. Para esa autora, factores como el tamaño del mercado, la presencia de razones estratégicas o la dotación de recursos naturales continúan siendo decisivos a la hora de explicar por qué los inversores se dirigen a un determinado país. Respecto de los inversores de origen estadounidense, Sullivan (2003) concluye que el marco de tratados bilaterales de protección influye poco al momento de definir el lugar donde localizar sus inversiones. ${ }^{16}$ Considerando

\footnotetext{
${ }^{15}$ Según la UNCTAD, los tratados desempeñan un papel menor en el destino de las corrientes de IED. Sin embargo, su rol puede ser más importante en determinadas circunstancias.

${ }^{16}$ El 80\% de la IED estadounidense se dirige a tres países (México, China y Brasil), con los cuales Estados Unidos no ha firmado acuerdo especial alguno sobre esta materia, excepto que un Tratado de Libre Comercio de América del Norte fue suscrito también por México.
} 
el aporte de los tratados bilaterales sobre inversiones al bienestar, Tobin y Rose-Ackerman (2003) concluyen que tales tratados parecerían tener un efecto a lo menos ambiguo, ya que no solo podrían ser perjudiciales en términos de flexibilidad sino que podrían terminar favoreciendo a los inversores extranjeros por sobre el conjunto de la población. En definitiva, los estudios citados ponen en duda la hipótesis de que los incrementos de la protección se traducen siempre en una mayor afluencia de IED, y señalan que, en cambio, acarrea compromisos internacionales muy significativos de los países receptores.

Para estos países, las ventajas se minimizan aún más, dado el sesgo en pro del inversor que este tipo de esquema consolida, tanto en lo que se refiere a los derechos del inversionista como a las garantías contra expropiaciones, especialmente aquellas consideradas "indirectas". Esta evolución se hace evidente en los nuevos tratados bilaterales sobre inversiones, cuya amplitud es cada vez mayor, imponiendo así mayores frenos a la acción gubernamental. Los inversores extranjeros también se ven favorecidos al momento de evaluar si una determinada medida del gobierno se considera expropiatoria, lo que ha hecho que las empresas "desafíen" cualquier intento de modificar las leyes y regulaciones vigentes (Stanley, 2004). Este fenómeno, que comienza a analizarse tras reclamos generalizados en el ámbito del Tratado de Libre Comercio de América del Norte, ${ }^{17}$ actualmente se expande hacia otras jurisdicciones (Moltke y Mann, 2004; Peterson, 2004). ${ }^{18}$

Lo anterior permite concluir que, en determinadas circunstancias, el esquema de tratados bilaterales sobre inversiones puede resultar perjudicial. Los derechos de los inversores han llegado tan lejos que podrían causar costos desproporcionados en los países receptores.

\footnotetext{
${ }^{17}$ Los sectores de salud y medio ambiente se encuentran entre los más afectados, por la presión de las empresas para que el Estado no altere las normas originales. La amenaza de pleito impone sobre la capacidad de regulación una limitación conocida como enfriamiento reglamentario (regulatory chill). Este fue uno de los fenómenos que dio inicio al debate en torno a la conveniencia del capítulo XI del Tratado de Libre Comercio de América del Norte.

${ }^{18}$ Fundamentalmente por obra de los nuevos tratados bilaterales sobre inversiones lanzados por los Estados Unidos. Los artículos citados comentan los casos de Sudáfrica y Malasia, donde el gobierno respectivo encuentra fuerte resistencia — de los inversores extranjeros - para imponer programas orientados a la igualdad racial o étnica.
}

\section{Naturaleza de la crisis argentina en materia de inversión extranjera directa}

El abrupto fin del esquema de paridad cambiaria abrió un nuevo frente de conflicto con los inversores extranjeros: en este caso, con aquellos que habían invertido en el sector real, especialmente en los servicios de utilidad pública. En virtud de los acuerdos ratificados en la década de 1990, ellos sintieron que tenían derecho a ser resarcidos totalmente por el gobierno. Ahora bien, aunque la mayoría de los inversores fueron afectados por el cambio de modelo, el mayor grupo de demandas provino de aquellos con algún tipo de interés en empresas prestadoras de servicios de utilidad pública, principalmente entre las vinculadas a la industria energética (gas y electricidad). ${ }^{19}$

El protagonismo de este tipo de inversores no solo se debió a las garantías que les brindaba el nuevo esquema bilateral (por ejemplo, el mecanismo de resolución de conflictos entre el Estado y el inversionista), sino también a lo establecido por la regulación nacional (por ejemplo, tarifas definidas en dólares y ajustadas según el índice de precios al por mayor de los Estados Unidos). El entramado contractual se componía de lo establecido en la legislación, lo pautado en términos de regulación, y lo acordado con terceros países mediante tratados bilaterales sobre inversiones que estaban garantizados en un ámbito judicial internacional independiente (el CIADI u otro tribunal arbitral). De esta forma, el gobierno, que perseguía asegurar la llegada de inversores y el éxito del esquema, terminó por reconocer un sistema de contratos "completos", aceptando así riesgos que no le correspondían.

Dicho mecanismo, que resultó funcional al gobierno argentino en su intento por mostrar su compromiso con normas internacionales, se convirtió en el principal escudo de los inversionistas extranjeros al momento de iniciarse la etapa judicial. El conjunto de restricciones que se impuso el gobierno (la normativa más los tratados) tenía por propósito minimizar la posibilidad de renegociación de los contratos con las empresas privatizadas, ya que la magnitud de los compromisos volvía costosa cualquier modificación, por necesaria que fuese. La crisis terminaría por comprobar el carácter "intrínsecamente incompleto" del esquema de

\footnotetext{
${ }^{19}$ Según el Instituto Internacional de Desarrollo Sostenible (IISD), los bonistas dejados fuera del canje de la deuda impuesto por el gobierno argentino y organizado en el Comité Global de Tenedores de Bonos Argentinos, planeaban demandar al Gobierno de Argentina vía juicio arbitral basado en tratados sobre inversiones (IIDS, 2005).
} 
contratos implícito en la regulación de las empresas privatizadas (Guash, Laffont y Straub, 2002; Navajas, 2004). Como resultado de la renuencia de nuevas administraciones a respetar los contratos firmados, algunos inversores comenzaron a retirarse - tal puede haber sido el caso de las empresas francesas EdF y France Telecom o de la empresa británica Nacional Grid- y se restringieron las inversiones necesarias para mantener la calidad de los servicios.

Esta ruptura originó un verdadero vendaval de demandas ante el CIADI. Actualmente el país enfrenta 42 demandas, ${ }^{20}$ incluyendo cuatro presentadas ante la Comisión de las Naciones Unidas para el Derecho Mercantil Internacional (CNUDMI), ${ }^{21}$ las cuales incrementan el pasivo contingente en un monto cercano a los 20.000 millones de dólares. Este monto podría elevarse apreciablemente si prosperara una serie de demandas potenciales ante el CIADI. ${ }^{22}$

Las medidas adoptadas por el gobierno afectaron la ecuación económico-financiera de los inversores. En el caso de los sectores regulados (con tarifas "pesificadas"), el impacto fue mayor cuanto más alto fuese el nivel de endeudamiento (en dólares). Esto llevó a que, con independencia del sector, la mayoría de las presentaciones efectuadas a partir del 2002 denunciara los efectos de la devaluación sobre los contratos en general y sobre el sistema de tarifas en particular. Según los inversores, el gobierno argentino había asumido el riesgo cambiario y tal promesa se había roto en enero del 2002.

Entre las empresas reguladas que hicieron presentaciones las más activas fueron las del sector energético (gas y electricidad), que iniciaron 22 demandas (19 ante el CIADI y tres ante la CNUDMI). Dada la fuerte integración (vertical y horizontal) existente en esta industria, dichas empresas no solo reclamaban por los efectos de la Ley de emergencia económica sobre las tarifas (pesificación y congelamiento), sino que también por sus efectos en los precios del sector desregulado (en el caso del gas, el precio de los insumos; en el caso de la electricidad, el precio de generación). Otra serie de demandas en el segmento regulado se originó en inversionistas, mayoritariamente de origen francés (cinco de un total de ocho presentaciones), con intereses en la prestación del servicio de agua potable

${ }^{20}$ Es importante destacar que, entre éstas, se incluyen cinco demandas que habían sido iniciadas cuando estaba en vigencia el régimen de convertibilidad.

21 Véase unctad (2005b).

22 Véase El cronista comercial (2005). y saneamiento. Un tercer grupo de presentaciones emanó de inversores con actividades en el sector de las telecomunicaciones (Telefónica S.A. de España y France Telecom S.A.). Otro conjunto de demandas aglutinó a inversionistas extranjeros que mantenían algún tipo de contrato con la administración pública, quienes reclamaron al Estado por ruptura de contrato. ${ }^{23}$ Un último grupo (seis presentaciones) involucró a empresas sin vínculo alguno con el gobierno, que demandaron al país por las consecuencias sobre sus pasivos que originó la devaluación.

Aunque en la mayoría de las presentaciones se señaló más de una causa, la "pesificación" de las tarifas fue el motivo principal de las demandas contra el país (Stanley, 2004). Pero, cualesquiera fuesen las razones esgrimidas, el inicio de la querella tuvo una motivación estratégica: la de posicionarse ante la renegociación. Esto significó que una vez sancionada la Ley de emergencia económica e interpuesta la demanda, se inició una pulseada entre el gobierno argentino, los inversores extranjeros (principalmente aquellos con participación en el sector privatizado) y las instituciones financieras internacionales (el Banco Mundial y el FMI).

La respuesta argentina puede describirse en pocas palabras como una suerte de cuestionamiento global. El gobierno nacional, a través de la Procuración del Tesoro, comenzó por impugnar al Tribunal, cuestionando su transparencia, el proceso de selección de árbitros y la posibilidad otorgada a los inversores de elegir tribunal (forum shopping). En la misma línea, el gobierno rechazó la injerencia del CIADI (por no reconocer su jurisdicción), alegando que las demandas deberían al menos ventilarse primero en los tribunales locales. Finalmente, al momento de defender su postura - los descargos del gobierno en el caso CMs Gas Transmission Company y el cuestionamiento de la jurisdicción en otros- la estrategia del gobierno se orientó a negar el carácter expropiatorio de las medidas que había interpuesto una vez declarada la emergencia económica, es decir, la "pesificación" y el congelamiento de las tarifas. ${ }^{24} \mathrm{El}$ efecto de la Ley de

\footnotetext{
${ }^{23}$ Las que podrían catalogarse como netamente defensivas, ya que surgieron como consecuencia de una ruptura contractual, pero con contratos fuertemente cuestionados (tres casos). Ante la amenaza de verse envuelto en una batalla legal con el gobierno, el inversor presenta una demanda ante el CIADI u otro tribunal arbitral con el objetivo de negociar con el país huésped el levantamiento de la medida inicial (denuncia).

${ }^{24}$ Véase en el anexo la lista de los casos contra Argentina en el
} CIADI. 
emergencia económica fue central en la estrategia del gobierno: todas las demandas reconocían una causal única, las medidas adoptadas a considerarse como las únicas factibles y los inversores debían soportar parte del costo del ajuste. En favor de Argentina puede plantearse que recientemente se han alzado varias voces (de académicos y actores políticos) que han expresado idénticos cuestionamientos al esquema arbitral. ${ }^{25} \mathrm{En}$ su contra juega la demora en renegociar los contratos con las empresas privatizadas, que ha generado malestar entre aquellos inversores dispuestos a ceder (parte o todo) en sus reclamos ${ }^{26}$ y puede hacer que por un período largo la afluencia de inversiones extranjeras directas esté por debajo de su nivel potencial.

Ante el rechazo de sus proposiciones y la desestimación de sus planteamientos, el gobierno reorientó su propuesta. Por un lado, intentó que las empresas privatizadas retiraran sus demandas, como gesto de buena voluntad de cara a la renegociación contractual. Con este propósito decidió iniciar conversaciones con los gobiernos de España y Francia, para que estos trataran de influir sobre sus inversores, con lo cual se politizarían las demandas. Por otro lado, y como consecuencia del fallo del tribunal arbitral en el caso CMs, el gobierno planteó que podría desconocer las posibles sanciones.

Por el lado de los inversores, las respuestas fueron variadas, destacando el interés estratégico que cada uno de ellos tenía al momento de iniciar la demanda. Un grupo, formado principalmente por inversionistas con intereses estratégicos en el país, comenzó a evaluar la conveniencia de renunciar a la demanda. ${ }^{27} \mathrm{Se}$ preveía que mantendrían sus demandas quienes habían

\section{IV}

\section{Conclusiones}

La naturaleza oscilante de la relación entre los inversores extranjeros y los países receptores, que a veces

\footnotetext{
25 Véase IIDS/wwF (2001), Mann y von Moltke (2002), Peterson (2003) y OCDE (2005a).

${ }^{26}$ Aspecto señalado también en el fallo del caso CMS (CIADI, 2005).

${ }^{27}$ Entre otras, se habrían retirado las demandas presentadas por: la Empresa Distribuidora y Comercializadora Sur S.A. (EDESUR), AES Corporation, Pioneer National Resources Co., Camuzzi, Gas Natural BAN, Empresa Distribuidora y Comercializadora Norte S.A. (EDENOR) y Unysis, lo que permitiría reducir el total reclamado en más de 4.000 millones de dólares (El cronista comercial, 2006).
}

optado por marcharse (inversores que participaban en empresas prestadoras de servicios de utilidad pública) o quienes habían entablado la demanda como respuesta defensiva, es decir, los inversores que alegaban que había habido ruptura contractual.

Las instituciones financieras internacionales fueron poco receptivas al planteamiento argentino. Inmediatamente después de la crisis, el Banco Mundial trató de condicionar un préstamo a la renegociación de las tarifas establecidas en los contratos de servicios de utilidad pública. La lenta reacción del CIADI y su indefinición frente a si eran o no de carácter expropiatorio las medidas adoptadas por el gobierno crearon incertidumbre, al menos, durante el período en el cual el FMI intentó presionar al país, antes de que el gobierno prepagara (anticipadamente) los préstamos del Fondo (9.000 millones de dólares).

Independientemente de las posturas y estrategias de los actores, el caso argentino dejó al desnudo lo inapropiado del actual esquema, dependiente del Banco Mundial, para la solución de diferencias entre el inversor y el país receptor. Al acaparar Argentina más del $40 \%$ de las demandas pendientes de resolución ante el CIADI, el problema dejó de ser del país demandado y pasó a ser del esquema arbitral. En términos legales, se puso de relieve lo inadecuado del sistema, que impide la acumulación de causas aun cuando la mayoría de las presentaciones contra Argentina obedecen a una misma razón (la ruptura contractual que siguió a la caída del régimen de convertibilidad). El país, por lo tanto, puede verse afectado por 40 fallos diferentes y quizás contradictorios (Goldhaber, 2004).

favorecía a los primeros (por ejemplo, con reglas internacionales que elevaban las garantías y la seguridad jurídica y la iniciativa de un acuerdo multilateral sobre inversiones en la órbita de la OCDE) y otras veces beneficiaba a los últimos (por ejemplo, con la inacción frente a la ola de nacionalizaciones del decenio de 1970 y el intento subsiguiente por establecer un código de conducta para las empresas transnacionales en el ámbito de las Naciones Unidas), resultó excesivamente propicia para los inversores extranjeros en la década de 1990. 
Antes de la crisis argentina, los inversores extranjeros habían logrado mejorar las garantías y seguridad legal que les brindaban los países en desarrollo y economías en transición, al introducir en sus contratos con los países deudores una serie de cláusulas por las cuales estos renunciaban a la inmunidad soberana en caso de cesación de pagos (lo mismo habían logrado los bancos transnacionales en el decenio de 1970 bajo el sistema de créditos en consorcio). Las garantías y ventajas para los inversionistas extranjeros también se ampliaron con la generalización del esquema bilateral y la introducción de un sistema de arreglo de diferencias relativas a inversiones que les permitía demandar al país huésped en forma directa.

Sin embargo, con la irrupción de la crisis argentina el sistema internacional dejó de proveer una solución tanto frente al incumplimiento soberano como a las pérdidas de los inversores extranjeros por la negativa del país receptor a aplicar las tarifas que habían sido estipuladas en el contrato original. Los "bonistas" quedaron espantados al ver que el FMI no podía obligar al gobierno argentino a renegociar su deuda siguiendo algún tipo de esquema preexistente, ni prestar asistencia a aquellos que se resistieron al canje (holdouts) a la espera de una mejor oferta del gobierno argentino. Idéntica sensación surgió entre los inversores extranjeros al comprobar que el Banco Mundial era incapaz de obligar a las autoridades argentinas a respetar lo originalmente pactado en los contratos sobre servicios de utilidad pública. Por su parte, el gobierno argentino, en su doble rol de deudor y de país huésped, quedó también consternado ante el funcionamiento del sistema internacional, por la forma en que éste favoreció explícitamente a los inversores extranjeros, la falta de objetividad de las instituciones financieras internacionales (fundamentalmente del FMI) y los intentos de condicionar la política económica del país al cumplimiento de los compromisos internacionales. En función de esto, y dada la dimensión social de la crisis ${ }^{28}$ el gobierno se vio forzado a elegir entre destinar recursos a paliar el deterioro social derivado de la crisis o dar cumplimiento a sus obligaciones internacionales con los inversores extranjeros. En definitiva, el sistema financiero internacional no suministró soluciones concretas al gobierno argentino para que este pudiera resolver la crisis múltiple por la que atravesaba el país.

\footnotetext{
${ }^{28}$ Entre 1999 y 2003 la proporción de argentinos que se hallaba por debajo de la línea de pobreza se duplicó, al pasar de 27,1 a 54,7\% de la población.
}

Lo expuesto nos lleva a considerar las principales enseñanzas que puede dejar el caso argentino respecto al funcionamiento del sistema institucional vigente. En primer lugar, vemos que las soluciones propuestas terminan siendo muy asimétricas, pues favorecen exageradamente a una de las partes inversoras extranjeras o países receptores, y carecen de viabilidad en el largo plazo. El interés de los inversores extranjeros por obtener más garantías a través de algún tipo de solución de mercado o de tratados bilaterales sobre inversiones (o, más recientemente, por medio de los capítulos sobre inversiones en los tratados de libre comercio) no parece ser, dado su fuerte sesgo, una respuesta adecuada a los problemas asociados a crisis graves. El nuevo enfoque de la administración estadounidense y el FMI respecto al tratamiento de las crisis financieras no ofrece salida ni protección a los inversores y sienta las bases para que surjan iniciativas unilaterales como la de Argentina.

En lo que se refiere al tratamiento de las inversiones, todos los intentos por establecer un esquema multilateral han resultado infructuosos, dadas las diferencias de opinión dentro del bloque de países inversores. Tampoco las ideas tras esos intentos son pertinentes hoy, si lo que se busca es resolver los problemas reales del mundo. Es tiempo de repensar la relación entre los inversores extranjeros y los países receptores para llegar a un esquema multilateral equitativo y duradero. Y para hacerlo puede ser interesante como punto de partida la reciente iniciativa de la Organización de Cooperación y Desarrollo Económicos (OCDE, 2005b) que desecha el enfoque anterior (AMI), por considerar que tenía elementos de intrusión y autoritarismo para con los países en desarrollo.

En segundo lugar, la experiencia argentina reciente sugiere que, ante una crisis múltiple, los gobiernos democráticos privilegian las necesidades de sus electores por sobre las demandas de los inversores extranjeros. Creer que los inversores extranjeros pueden obtener más garantías y protección legal continuas mediante el fortalecimiento del esquema bilateral, es olvidar que las negociaciones multilaterales constituyen el único marco en el cual los países en desarrollo y las economías en transición mantienen un espacio para negociar. Aunque hasta ahora no se haya podido alcanzar algún tipo de acuerdo multilateral para la solución de las crisis financieras o de las diferencias sobre inversiones, esta sigue siendo la mejor opción para los países en desarrollo, por sus beneficios en términos de equidad, y para los inversores externos, por ofrecer una predictibilidad mayor. A largo plazo, esto puede también implicar más credibilidad. 
Cabe preguntarse, por último, si la experiencia argentina permite suponer que la protección otorgada a los inversores extranjeros terminó jugándoles en contra, al verse obligados a aceptar las condiciones del gobierno argentino. Aunque esto talvez no haya sido así, la situación descrita puede presentarse a mediano plazo. ${ }^{29}$ Actualmente se observa un creciente cuestionamiento de las instituciones financieras internacionales, que favorecen a los inversores extranje- ros sin brindar soluciones concretas a los países en desarrollo frente a crisis financieras o a disputas cada vez más numerosas en materia de inversión. El desencanto con esas instituciones es una de las tantas manifestaciones del cuestionamiento cada vez mayor de los modelos de ajuste basados en el mercado que aplicó América Latina en la década de 1990, siendo excesivo en ellos el sesgo pro mercado y limitados los beneficios.

\section{Bibliografía}

Banco Mundial (2004): Global Development Finance 2004, Washington, D.C., versión en CD-ROM.

CEPAL (Comisión Económica para América Latina y el Caribe) (1989): EL comportamiento de los bancos transnacionales y la crisis internacional de endeudamiento, serie Estudios e informes de la CEPAL, No 76, LC/G.1533/Rev.1-P, Santiago de Chile, julio. Publicación de las Naciones Unidas, $\mathrm{N}^{\circ}$ de venta: S.89.II.G.12.

CET (Centro de las Naciones Unidas sobre las Empresas Transnacionales) (1990): Debt Equity Conversions: A Guide for Decision-makers, ST/CTC/104, Nueva York. Publicación de las Naciones Unidas, $\mathrm{N}^{\circ}$ de venta: 90.II.A.22.

CIADI (Centro Internacional de Arreglo de Diferencias Relativas a Inversiones) (2005): Case No. ARB/01/8, Award in the proceeding between CMS Gas Transmission Company and the Argentine Republic, 12 de mayo, Washington, D.C.

Dañino, R. (2005): Opening Remarks, Simposio CIADI/OCDE/UNCTAD "Making the Most of International Investment Agreements: a Common Agenda" (París, 12 de diciembre).

Eichengreen, B. (1988): Resolving Debt Crises: An Historical Perspective, NBER Working Paper Series, N ${ }^{\circ} 2555$, Cambridge, Massachusetts, National Bureau of Economic Research.

Eichengreen, B., R. Portes y otros (1995): Crisis, What Crisis? Orderly Workouts for Sovereign Debtors, Londres, Centro de Investigación sobre Políticas Económicas (CEPR).

El cronista comercial (2005): Buenos Aires, 13 de mayo. (2006): Buenos Aires, 2 de enero.

Gerchunoff, P. y G. Cánovas (1995): Privatizaciones en un contexto de emergencia económica, Desarrollo económico, vol. 34, $\mathrm{N}^{\mathrm{o}}$ 136, Buenos Aires, Instituto de Desarrollo Económico y Social (IDES), enero-marzo.

Goldhaber, M. (2004): Wanted: a world investment court, The American Lawyer, Nueva York, disponible en http://www.american laywer.com/focuseurope/investmentcourt04.html.

Guash, J.L., J.J. Laffont y S. Straub (2002): Renegotiation of Concession Contracts in Latin America, disponible en SSRN electronic journal http://papers.ssrn.com/abstract_id=340580.

G-10 (Grupo de los Diez) (1996): The Resolution of Sovereign Liquidity Crisis, Washington, D.C., Fondo Monetario Internacional.

${ }^{29}$ En rigor de verdad, será difícil que se repita la situación argentina, no por la audacia de la estrategia que siguió el país en el momento del canje de la deuda ni por su actitud en la renegociación con los inversores, sino por el origen de lo sucedido: el exceso de garantías que otorgó el gobierno en la década de 1990.
Hallward-Driemeier, M. (2003): Do Bilateral Investment Treaties Attract FDI? Only a Bit... and They Could Bite, Policy Research Working Paper, No WPS 3121, Washington, D.C., Banco Mundial.

IFI (Instituto de Finanzas Internacionales) (1999): Involving the Private Sector in Forestalling and Resolving Financial Crises: Collective Action Provisions in International Sovereign Bonds, Washington, D.C., Fondo Monetario Internacional, agosto.

(2001): Involving the Private Sector in the Resolution of Financial Crises: Restructuring International Sovereign Bonds, Washington, D.C., Fondo Monetario Internacional, enero.

IIDS (Instituto Internacional para el Desarrollo Sostenible) (2005): Argentine bondholders girding for multi-billion dollar investment treaty claim, Invest-SD: Investment Law and Policy News Bulletin, Winnipeg, Manitoba, Canadá, 10 de junio.

IIDS/WWF (Instituto Internacional para el Desarrollo Sostenible/Fondo Mundial para la Naturaleza) (2001): Derechos privados, problemas públicos: una guía sobre el controvertido capítulo del TLCAN referente a los derechos de los inversionistas, Winnipeg, Manitoba, Canadá.

Kydland, E. y E. Prescott (1977): Rules rather than discretion: the inconsistency of optimal plans, Journal of Political Economy, vol. 85, No 3, Chicago, The University of Chicago Press.

Machinea, J.L. (2002): La crisis de la deuda, el financiamiento internacional y la participación del sector privado, serie Financiamiento del desarrollo, $\mathrm{N}^{\circ}$ 117, LC/L.1713-P, Santiago de Chile, Comisión Económica para América Latina y el Caribe (CEPAL). Publicación de las Naciones Unidas, $\mathrm{N}^{\circ}$ de venta: S.02.II.G.23.

Mann, H. y K. von Moltke (2002): La protección de los derechos de los inversionistas y del bienestar público: evaluación del capítulo XI del TLCAN, documento presentado en los talleres del Proyecto del IIDS sobre el derecho de la inversión y el desarrollo sustentable (México, D.F., 11 de marzo; Ottawa, 18 de marzo; y Washington, D.C., 11 de abril). Disponible en http://www.iisd.org/trade/ILSDWorkshop.

Moltke, von K. y H. Mann (2004): Towards a Southern Agenda on International Investment: Discussion Paper on the Role of International Investment Agreements, Winnipeg, Manitoba, Canadá, Instituto Internacional para el Desarrollo Sostenible (IIDS).

Mortimore, M. (1989): Conductas de los bancos acreedores de América Latina, Revista de la CEPAL, No 37, LC/G.1547-P, Santiago de Chile, abril.

Navajas, F. (2004): Reformas en el sector de infraestructura en la Argentina - Algunos comentarios, presentación para el Proyecto "Balance del proceso de transformación de los servicios de infraestructura en la República Argentina", Buenos Aires, Federación Interamericana de Empresas de Seguros (FIDES). 
OCDE (Organización de Cooperación y Desarrollo Económicos) (2005a): Improving the System of Investor: State Dispute Settlement: an Overview, documento presentado en el Simposio CIADI/OCDE/UNCTAD "Making the Most of International Investment Agreements: A Common Agenda" (París, 12 de diciembre).

(2005b): A Policy Framework for Investment: Draft Preamble, Checklists and Preliminary Annotations, documento presentado en la Conferencia de la OCDE "Investment for Development: Making It Happen” (Río de Janeiro, 25 al 27 de octubre de 2005), París.

Peterson, L.E. (2003): All Roads Lead out of Rome: Divergent Paths of Dispute Settlement in Bilateral Treaties, International Sustainable and Ethical Investment Rules Project, Nautilus Institute for Security and Sustainable Development, San Francisco, California.

(2004): Bilateral Investment Treaties and Developing Policy-Making, Winnipeg, Manitoba, Canadá, Instituto Internacional para el Desarrollo Sostenible (IIDS).

Roubini, N. (2005): The Successful End of the Argentina Debt Restructuring Saga, disponible en http://www.rgemonitor.com/342.

Sachs, J. (1995). Do we need an international lender of last resort, Frank D. Graham Lecture, Princeton, Princeton University, 20 de abril. Disponible en http://www.ksg.harvard.edu/cid/ ciddirector/publicat.htlm\#Working.

Stallings, B. y W. Peres (2000): Crecimiento, empleo y equidad: el impacto de las reformas económicas en América Latina y el Caribe, Santiago de Chile, Fondo de Cultura Económica/ Comisión Económica para América Latina y el Caribe (CEPAL).
Stanley, L. (2004): Acuerdos bilaterales de inversión y demandas ante tribunales internacionales: la experiencia argentina reciente, serie Desarrollo productivo, $\mathrm{N}^{\circ} 158$, LC/L.2181-P, Santiago de Chile, Comisión Económica para América Latina y el Caribe (CEPAL), septiembre. Publicación de las Naciones Unidas, $\mathrm{N}^{\circ}$ de venta: S.04.II.G.108.

Sullivan, N. (2003): Bilateral Investment Treaties as a Determinant of U.S. Foreign Direct Investment in Developing Countries, Boston, Massachusetts, Money Matters Institute, disponible en http:// www.moneymattersinstitute.org/html/investment_treaties.html.

The Economist (2005): Argentina's debt restructuring: A victory by default, Londres, 3 de marzo.

Tobin, J. y S. Rose-Ackerman (2003): Foreign Direct Investment and the Business Environment in Developing Countries: The impact of Bilateral Investment Treaties, WDI Working Paper $N^{\circ} 587 / 03$, Michigan, The William Davidson Institute at the University of Michigan Business School.

UNCTAD (Conferencia de las Naciones Unidas sobre Comercio y Desarrollo) (1998): Bilateral Investment Treaties in the Mid1990s, UNCTAD/ITE/IIT/7, Nueva York, Naciones Unidas. Publicación de las Naciones Unidas, $\mathrm{N}^{\mathrm{o}}$ de venta: E.98.II.D.8. (2005a): World Investment Report 2005: Transnational Corporations and the Internationalization of $R \& D$, UNCTAD/ WIR/2005, Ginebra, Naciones Unidas, septiembre. Publicación de las Naciones Unidas, $\mathrm{N}^{\mathrm{o}}$ de venta: E.05.II.D.10.

(2005b): Latest Developments in Investor-State Dispute Settlement, IIA Monitor, No 4, UNCTAD/WEB/ITE/IIT/2005/2, Ginebra, Naciones Unidas, diciembre. 


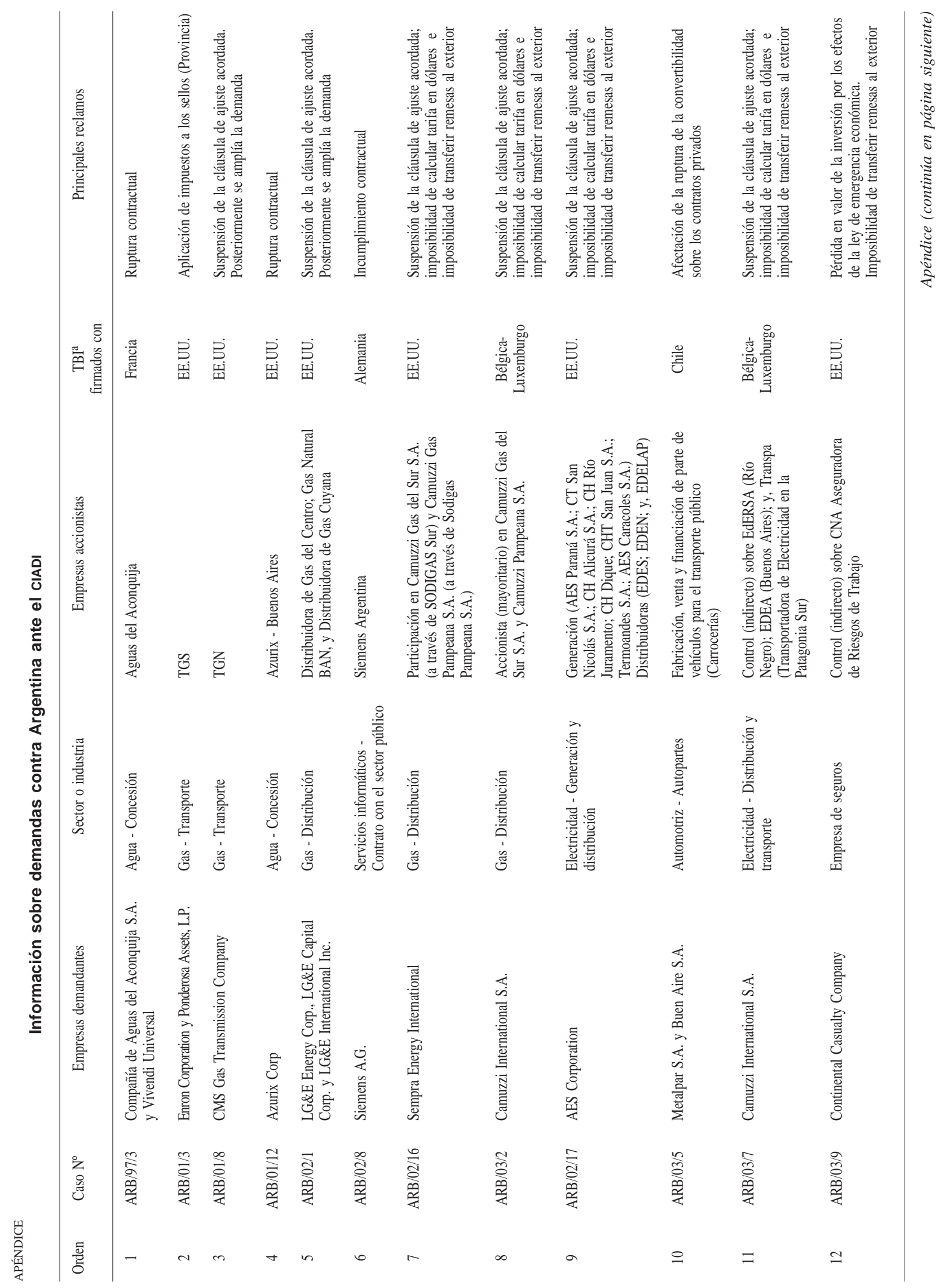




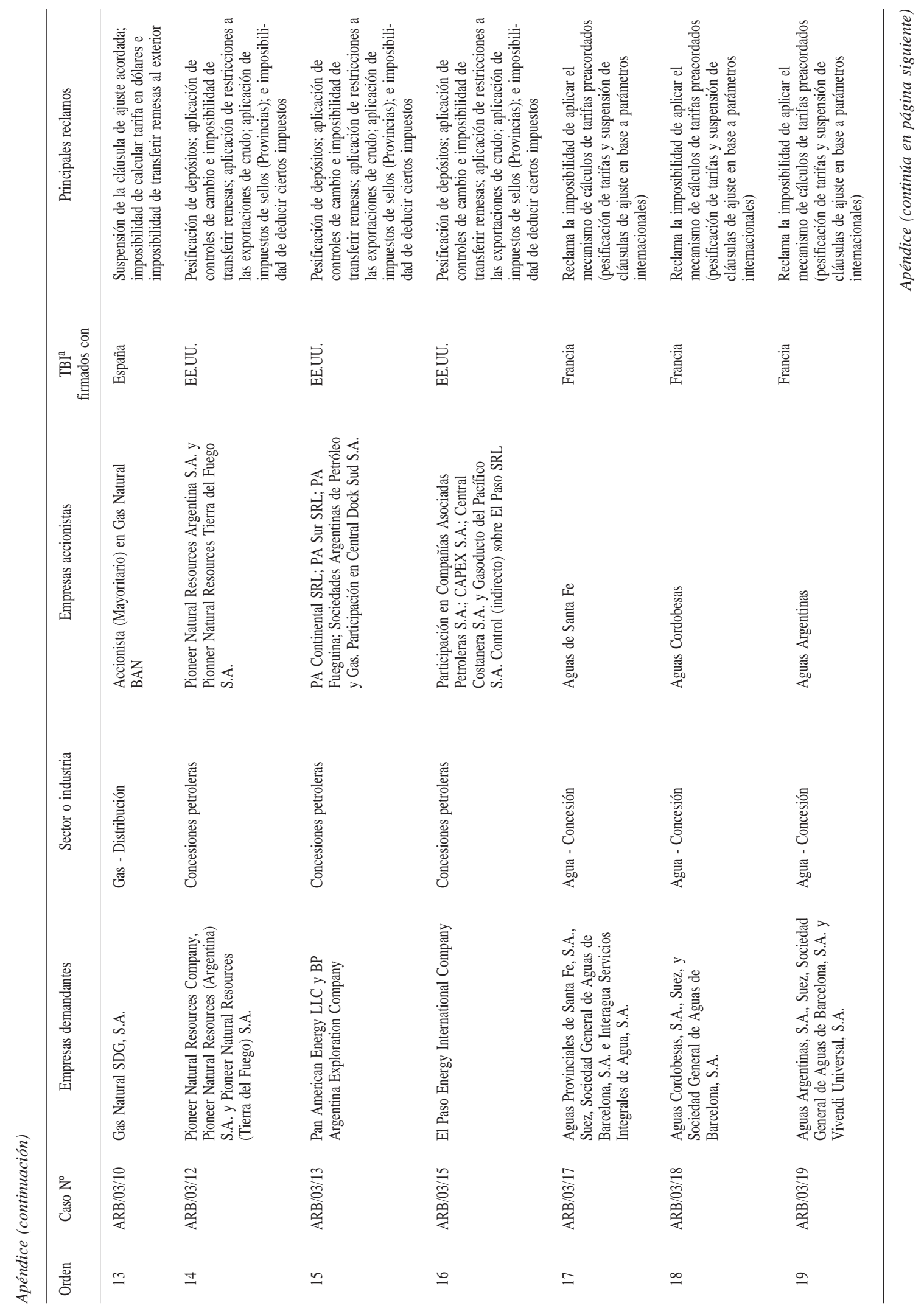




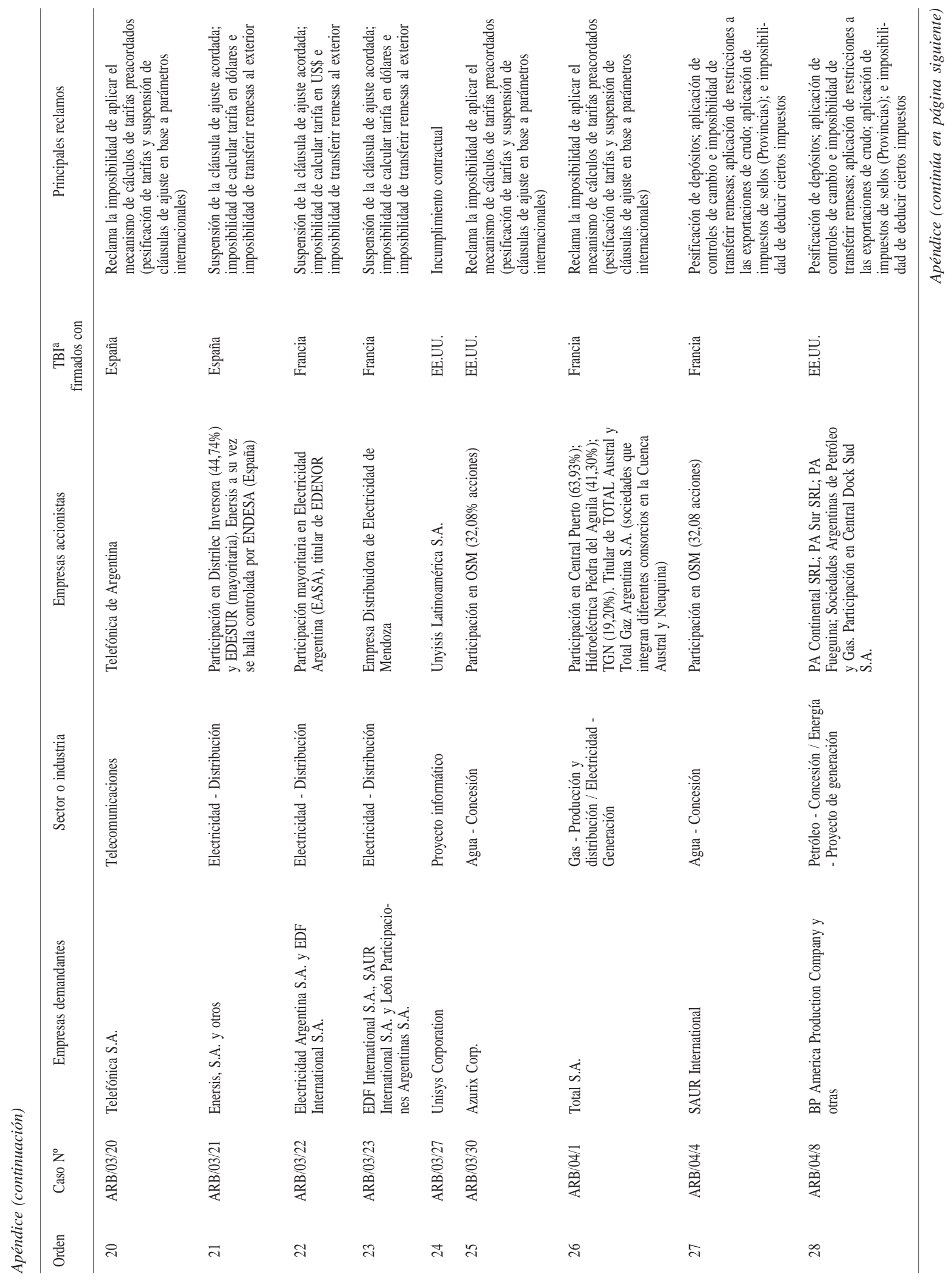




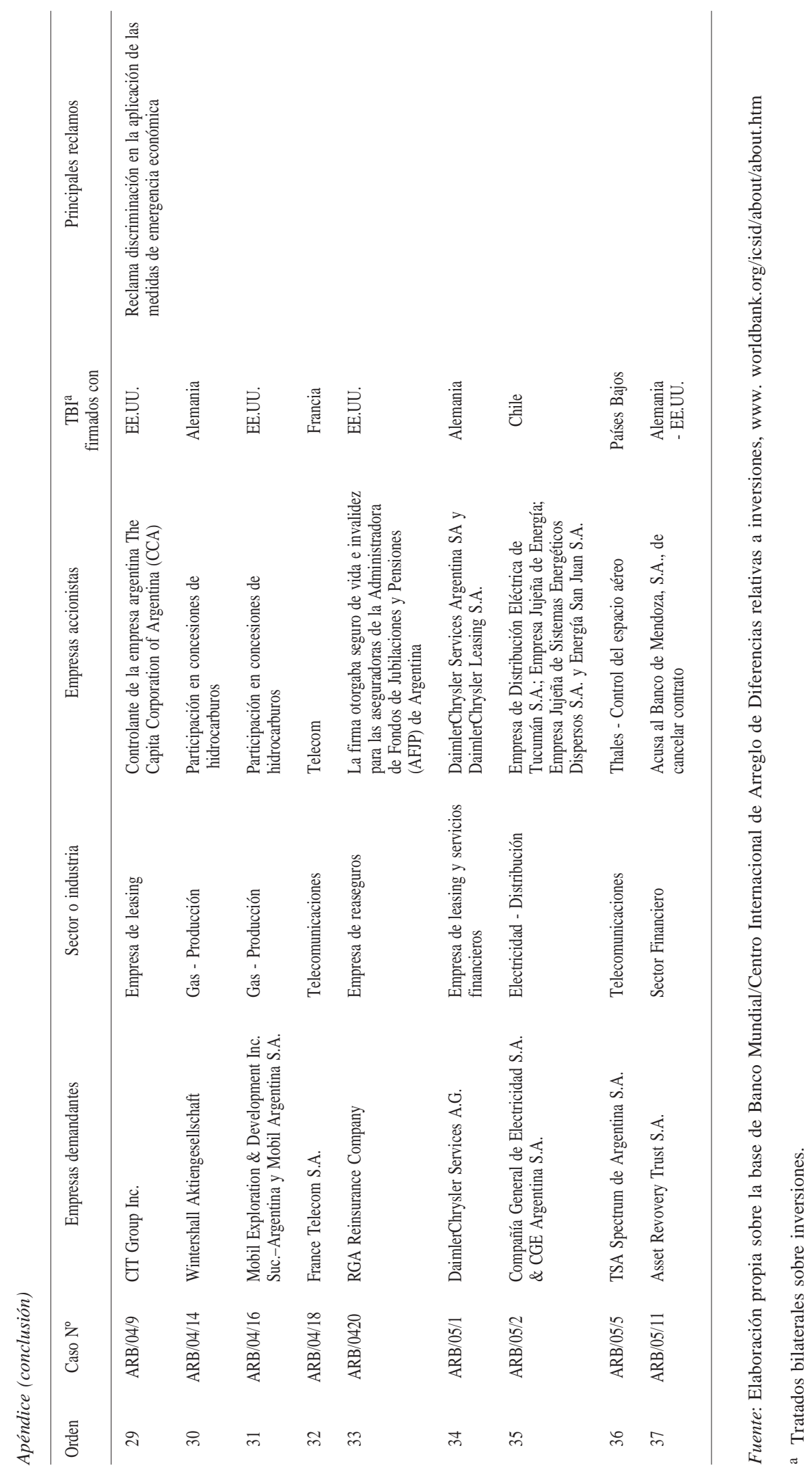

